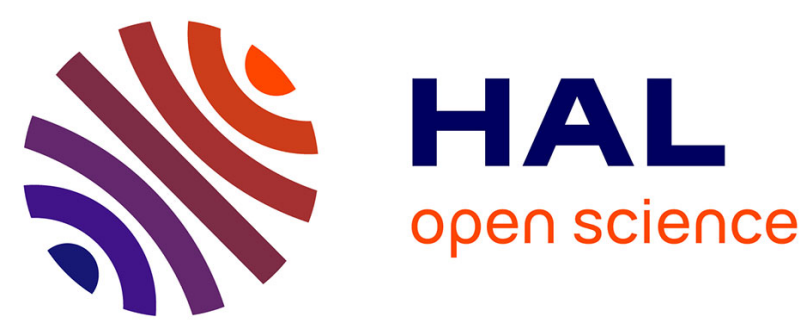

\title{
Highly concentrated collagen solutions leading to transparent scaffolds of controlled three-dimensional organizations for corneal epithelial cell colonization
} Aurelien Tidu, Djida Ghoubay-Benallaoua, Claire Teulon, Sophie Asnacios, Kate Grieve, François Portier, Marie-Claire Schanne-Klein, Vincent M. Borderie, Gervaise Mosser

\section{To cite this version:}

Aurelien Tidu, Djida Ghoubay-Benallaoua, Claire Teulon, Sophie Asnacios, Kate Grieve, et al.. Highly concentrated collagen solutions leading to transparent scaffolds of controlled three-dimensional organizations for corneal epithelial cell colonization. Biomaterials Science, 2018, 6 (6), pp.1492-1502. 10.1039/c7bm01163f . hal-02124421

\section{HAL Id: hal-02124421 \\ https://hal.sorbonne-universite.fr/hal-02124421}

Submitted on 9 May 2019

HAL is a multi-disciplinary open access archive for the deposit and dissemination of scientific research documents, whether they are published or not. The documents may come from teaching and research institutions in France or abroad, or from public or private research centers.
L'archive ouverte pluridisciplinaire HAL, est destinée au dépôt et à la diffusion de documents scientifiques de niveau recherche, publiés ou non, émanant des établissements d'enseignement et de recherche français ou étrangers, des laboratoires publics ou privés. 


\section{Highly concentrated collagen solutions leading to transparent scaffolds of controlled three-dimensional organizations for corneal epithelial cell colonization.}

Aurélien Tidu ${ }^{1 \#}$, Djida Ghoubay-Benallaoua ${ }^{2 \#}$, Claire Teulon ${ }^{4}$, Sophie Asnacios ${ }^{5}, \mathrm{Kate}_{\mathrm{Grieve}}{ }^{2}$, François Portier $^{1}$, Marie-Claire Schanne-Klein ${ }^{4}$, Vincent Borderie ${ }^{2^{*}}$, Gervaise Mosser ${ }^{1 *}$

${ }^{1}$ Sorbonne Université, CNRS, Collège de France, Laboratoire Chimie de la Matière Condensée de Paris, LCMCP, F-75005 Paris France.

${ }^{2}$ Sorbonne Université, Institut de la Vision, INSERM, CNRS Centre Hospitalier National d'Ophtalmologie des Quinze-Vingts, F-75012 Paris France..

${ }^{4}$ Laboratory for Optics and Biosciences, LOB, Ecole Polytechnique, CNRS, Inserm, Université Paris-Saclay, F-91128 Palaiseau France.

${ }^{5}$ Sorbonne Université, CNRS, Univ Paris Diderot, Laboratoire Matière et Systèmes Complexes, MSC, F-75013 Paris, France.

\#Equally first authors.

*Corresponding Authors.

KEYWORDS: Collagen; Liquid Crystal; Biomaterials; Transparency, Rheology, Corneal Epithelial Stem cells, 


\section{ABSTRACT}

This study aimed at controlling both the organization and the transparency of dense collagen scaffolds making use of the lyotropic mesogen properties of collagen. Cholesteric or plywoodlike liquid crystal phases were achieved using mixtures of acetic and hydrochloric acids as solvents. The critical $\mathrm{pH}$ at which the switch between the two phases occurred was around $\mathrm{pH}=3$. The use of the two acids led to fibrillated collagen I scaffolds, which visual aspect ranged from opaque to transparent. Rheological investigations showed that viscoelastic properties of the plywood-like solutions were optimized for molding due to faster recovery. They also confirmed the correlation between the elastic modulus and the diameter of collagen fibrils obtained after fibrillogenesis under ammonia vapor. Human corneal epithelial cells, grown from donor limbal explants, were cultured both on transparent plywood-like matrix and on human amniotic membranes for 14 days. The development of corneal epithelium and the preservation of epithelial stem cells were checked by optical microscopy, colony formation assay, immunofluorescence and quantitative polymerase chain reaction. A higher level of amplification of limbal stem cells was obtained with collagen matrices compared with amniotic membranes, showing the high biocompatibility of our scaffolds. We therefore suggest that collagen solutions presenting both plywood-like organization and transparency might be of interest for biomedical applications in ophthalmology.

\section{INTRODUCTION}


Collagen type I is the major structural protein in connective tissues. It exhibits highly organized fibrillar distributions in various tissues ranging from bone to dermis and including cornea. As such, it is found organized in different manners and must also fulfill different physical requirements from hard to soft and from opaque to transparent. ${ }^{1}$ Collagen is a semi-flexible biopolymer $(1.5 \mathrm{~nm}$ diameter and approximately $300 \mathrm{~nm}$ in length) made of three polypeptide chains arranged in a right-handed triple helix. Two of these polypeptide chains have the same primary sequence $(\alpha 1)$ while the third chain is different $(\alpha 2)$. In their central portion, these three chains are formed by the repetition of a triplicate of the amino-acids sequence Gly-X-Y. Proline and hydroxyproline are the most common amino acids found in $\mathrm{X}$ and $\mathrm{Y}$ positions respectively. ${ }^{2}$ In vitro, acidic collagen I solutions have lyotropic properties, meaning that collagen I molecules self organize in liquid crystal phases as soon as a critical concentration of collagen is reached. The liquid crystal phase and the concentration of the isotropic/liquid crystal transition depend on the physicochemical conditions. ${ }^{3,4,5,6,7}$ These liquid crystal organizations of concentrated collagen can be stabilized thanks to a $\mathrm{pH}$ increase. This increase induces a sol-gel transition via the formation of fibrils while preserving the long-range organization set in the liquid phase. This two-step process creates organized fibrillar matrices whose organizations mimic that of extracellular matrices (ECM) in living tissues such as bone, dermis or cornea ${ }^{8,9,10,11}$ with microstructure of the fibrils depending on the physicochemical conditions used during the synthesis of the scaffolds. ${ }^{12}$

Being a transparent tissue, cornea, the outer layer and first lens of the eye, is a most particular connective tissue. Its major layer, the stroma, accounts for more than $90 \%$ of the cornea thickness ${ }^{13}$ and is mainly composed of ECM. Collagen I is the major component of the stroma, which also contains other biomolecules such as collagen V and VI or proteoglycans. ${ }^{14,15,16,17}$ In 
corneal stroma, collagen fibrils are described as organized in lamellae of approximately 0.2 to $2.5 \mu \mathrm{m}$ thickness $^{18}$ and 300 to 500 such lamellae are found piled up throughout the whole stromal thickness. These lamellae are constituted of micrometric domains of aligned collagen fibrils. Those domains vary in size from posterior (60 to $250 \mu \mathrm{m})$ to anterior (10 to $40 \mu \mathrm{m})$ stroma. ${ }^{19}$ Within each domain, the fibrils are approximately parallel and the interfibrillar distance is $35 \mathrm{~nm}$ on average with a fibril diameter of $25-35 \mathrm{~nm}$, although some variations were observed from anterior to posterior stroma. ${ }^{16,20}$ The lamellae are set as in a plywood with a change of roughly $90^{\circ}$ in the alignment direction of collagen fibrils between adjacent lamellae, at least at the center of the tissue. ${ }^{21}$

Cornea disorders are not only cause of blindness ( $4^{\text {th }}$ cause) but also take part in refractive errors affecting $\quad$ some million people over the world. (http://www.who.int/blindness/causes/priority/en/index8.html). ${ }^{22}$ Even though corneal allograft remains the gold standard to treat non-inflammatory diseases leading to a loss of vision, such as keratoconus, only $1 \%$ of the patients can receive a corneal transplant. This deficit, due to an imbalance between donor supply and patient demand, poses a public health problem and tremendous efforts are currently being made to develop different strategies to overcome it. Alternative treatments such as synthetic corneal implants can be used. Artificial cornea substitutes have been fabricated with synthetic polymers such as pHEMA or PMMA. ${ }^{23,24}$, However, synthetic materials act as prosthesis without restoring the original state of the organ and with risks such as extrusion or erosion, chronic inflammation or necrosis. Thus, to overcome the disadvantages of synthetic materials for corneal repair, collagen-based implants are being developed by several research groups around the world. ${ }^{10,25,26,27,28,29,30}$ Most often these implants are made at low collagen concentration with additives to cross-link the collagen and obtain a 
corneal implant with high transparency as well as sufficient mechanical stability but with some potential cytotoxicity issues.

Our approach is to synthesize a collagen-based artificial cornea without any additives, by exploiting the inherent liquid crystal properties of collagen molecules. ${ }^{7}$ The present work aimed at analyzing the key parameters to control the liquid crystal phase and the fibril diameter of collagen. In particular, we studied the association of two acids, hydrochloric and acetic acids $\left(\mathrm{HCl}\right.$ and $\left.\mathrm{CH}_{3} \mathrm{COOH}\right)$ and tested a set of conditions for transparency and liquid crystal organization. The liquid crystal organization formed in glass-microchambers ${ }^{31}$ were visualized by polarized light and second harmonic generation (SHG) microscopies. Thanks to its 3D imaging capability and its specificity for non centro-symmetrical structures ${ }^{32,33,34}$ SHG allowed selection of the optimal physicochemical conditions, i.e. those leading to a plywood organization like the one found in cornea. Linear viscoelastic properties of solutions giving different organizations and leading to transparent scaffolds were investigated in order to better understand the relation between solutions and engineered scaffolds. Finally, our best condition was checked for epithelial cell culture and compared to culture on amniotic membrane.

\section{MATERIALS AND METHODS}

Preparation of collagen solutions. Tendons were extracted from wild-type rat-tails and collagen was purified as already described ${ }^{30}$. Aliquots of the final collagen solution (stock solution 500 $\mathrm{mM}$ acetic acid $\left(\mathrm{CH}_{3} \mathrm{COOH}\right)$, condition 4 in Table 1) were made in sterile tubes and stored at $4^{\circ} \mathrm{C}$ until use. Prior to use, stock solutions were dialyzed against media of different physicochemical conditions combining hydrochloric acid $(\mathrm{HCl})$ and acetic acid as detailed in 
Table 1. The specific concentrations of acetic and hydrochloric acids were adjusted by repeated cycles of dialysis (Spectra/Pore ${ }^{\circledR}$ 12-14,000 Da, $6.4 \mathrm{~mL} / \mathrm{cm}$ ). A first panel of arbitrary conditions were tested and then further pinned down around conditions giving transparent matrices.

\begin{tabular}{|l|l|l|l|l|l|l|l|l|l|l|l|l|l|l|}
\hline TABLE 1 \\
\hline Condition $\mathbf{N}^{\circ}$ & $\mathbf{1}$ & $\mathbf{2}$ & $\mathbf{3}$ & $\mathbf{4}$ & $\mathbf{5}$ & $\mathbf{6}$ & $\mathbf{7}$ & $\mathbf{8}$ & $\mathbf{9}$ & $\mathbf{1 0}$ & $\mathbf{1 1}$ & $\mathbf{1 2}$ & $\mathbf{1 3}$ & $\mathbf{1 4}$ \\
\hline \hline $\mathbf{C H}_{\mathbf{3}} \mathbf{C O O H}$ & 5 & 200 & 300 & 500 & 2 & 5 & 10 & 20 & 36 & 120 & 220 & 320 & 36 & 120 \\
\hline $\mathbf{H C l}$ & 0 & 0 & 0 & 0 & 0.3 & 0.3 & 0.3 & 0.3 & 0.3 & 0.3 & 0.3 & 0.3 & 0.6 & 0.6 \\
\hline $\mathbf{p H}$ & 2.7 & 2.77 & 2.7 & 2.55 & 3.45 & 3.37 & 3.26 & 3.17 & 2.93 & 2.85 & 2.61 & 2.57 & 2.91 & 2.73 \\
\hline $\mathbf{C o n d i t i o n ~}^{\circ}$ & $\mathbf{1 5}$ & $\mathbf{1 6}$ & $\mathbf{1 7}$ & $\mathbf{1 8}$ & $\mathbf{1 9}$ & $\mathbf{2 0}$ & $\mathbf{2 1}$ & $\mathbf{2 2}$ & $\mathbf{2 3}$ & $\mathbf{2 4}$ & $\mathbf{2 5}$ & $\mathbf{2 6}$ & $\mathbf{2 7}$ & $\mathbf{2 8}$ \\
\hline $\mathbf{C H}_{\mathbf{3}} \mathbf{C O O H}$ & 220 & 36 & 120 & 220 & 36 & 75 & 120 & 200 & 300 & 500 & 800 & 36 & 120 & 220 \\
\hline $\mathbf{H C l}$ & 0.6 & 0.9 & 0.9 & 0.9 & 1.25 & 1.25 & 1.25 & 1.25 & 1.25 & 1.25 & 1.25 & 1.5 & 1.5 & 1.5 \\
\hline $\mathbf{p H}$ & 2.58 & 2.85 & 2.69 & 2.59 & 2.78 & 2.55 & 2.71 & 2.67 & 2.64 & 2.53 & 2.33 & 2.7 & 2.54 & 2.63 \\
\hline
\end{tabular}

Table 1. Set of physicochemical conditions. A condition is defined by its concentrations in acetic acid and hydrochloric acid. Solutions of collagen in each physicochemical condition were prepared to create scaffolds. The underlined conditions are those, which were previous described. ${ }^{6,7,31,35}$.

These collagen solutions were then concentrated in two different ways: (i) Concentration of small collagen quantities under various conditions was achieved in glass microchambers by slow injection of diluted collagen compensating for evaporation (see below characterization of liquid crystal phases). (ii) Concentration of larger quantities for scaffold synthesis was achieved by setting collagen solutions into VIVASPIN concentrators (100kD cut-off) and centrifuging until the desired concentration was reached (Beckman Coulter J26-XP centrifuge, $4922 \mathrm{~g}, 10{ }^{\circ} \mathrm{C}$ ). Prior to use, the concentrated solutions were set into sterile syringes and centrifuged to eliminate air bubbles. 
Scaffolds synthesis. Collagen dense solutions $(60,90,120 \mathrm{mg} / \mathrm{mL})$ were extruded and shaped in glass molds, which were either flat or curved with curvatures mimicking human cornea (mold made by Verrerie Villeurbannaise). Once molded, solutions were submitted to ammonia vapor for 24 hours (unless otherwise mentioned) to neutralize the charges of the collagen and achieve fibrillogenesis. They were subsequently collected and immediately set into sterile tubes filled with water until use. The thickness of the scaffolds were fixed either by using glass bottommolds with a $500 \mu \mathrm{m}$ depression or by using $500 \mu \mathrm{m}$ thick spacers placed in between top and lower flat glass surfaces. The final thicknesses of the scaffolds right after fibrillogenesis were $500 \mu \mathrm{m}$.

Transmittance assessment. Scaffolds transparency was assessed as already described using a UVIKON XL spectrophotometer. ${ }^{30}$ The absorbance of the sample was determined by $T=$ $10-D m * d$ where $\mathrm{D}_{\mathrm{m}}$ was the average optical density for $\lambda$ varying between 340 and $780 \mathrm{~nm}$. For a given wavelength $\lambda$, the optical density was obtained as $D(\lambda)=A_{\text {sample }}(\lambda) / d$ where $d$ was the sample thickness and A, the measured absorbance.

Characterization of liquid crystals phases. Since our ultimate goal was the synthesis of fibrillated pure transparent collagen scaffolds mimicking the plywood-like organization of the corneal stroma, we only characterized the organizations induced in collagen solutions giving transparent scaffolds. Liquid crystal organizations were checked in custom-built glass microchambers as described in previous papers. ${ }^{7,31}$ The critical concentration in collagen at which transition from isotropic to plywood organization occurred was determined by checking the relaxation of collagen solutions at different concentrations as already described. ${ }^{6}$ All experiments were repeated at least three times for each physicochemical condition. The organizations were analyzed by Polarized Light Microscopy (PLM) on a Nikon Eclipse E600Pol 
microscope equipped with a 40x/0.65 NA objective and a DXM 1200 CCD camera as already described. ${ }^{7,31}$

The liquid crystalline samples were also imaged by Second Harmonic Generation microscopy (SHG), which specifically reveals aligned assemblies of collagen molecules or fibrils. ${ }^{32}$ We used a custom-built laser-scanning multiphoton microscope as previously described ${ }^{36}$ and also recorded endogenous two-photon excited fluorescence (2PEF) from collagen to assess collagen density. Excitation was provided by a femtosecond Titanium-Sapphire laser (Mai-Tai, SpectraPhysics) tuned to $860 \mathrm{~nm}$ and focused using a 60x 1.2 NA objective lens (UplanSApo, Olympus), with typically $0.3 \mu \mathrm{m}$ (lateral) x $0.9 \mu \mathrm{m}$ (axial) resolution. Circular polarization was used in order to image all structures independently of their orientation in the focal plane. SHG and 2PEF signals were simultaneously detected in two channels equipped with appropriate spectral filters. Power at the sample was typically 3 to $10 \mathrm{~mW}$ with $10 \mu \mathrm{s} /$ pixel acquisition time. Stacks of 2D images at increasing depth were acquired with $0.16 \mu \mathrm{m}$ lateral pixel size and $1 \mu \mathrm{m}$ axial step to generate a 3D data set.

The samples were fixed and embedded in araldite as already described ${ }^{11,30,31}$ then analyzed by Transmission Electron Microscopy (TEM). Sections were obtained either on an Ultracut Reichert Jung or on a Leica EM UC7. 70 nm thick sections, stained with uranyl acetate, were observed on a transmission electron microscope FEI Tecnai spirit G2 operating at $120 \mathrm{kV}$. Images were recorded on a CCD Camera (Orius Gatan 832 digital).

Rheology. Rheological measurements were carried on in a cone-and-plate cell (40 $\mathrm{mm}$ in diameter, angle of $0.04 \mathrm{rad}$ ) of a stress-controlled rheometer (SR500 Rheometrics) as already described. ${ }^{37}$ The temperature was controlled using water circulating from a thermo-regulated bath. The cell was covered and the atmosphere, inside the cell, was saturated with the same acid 
mix as the collagen solution under study. To prevent slip, cone and plate were roughened with sandblasting. Before each experiment, the sample was let at rest for one hour before starting small-amplitude oscillatory experiments. The shear storage and loss modulus (respectively G' and G',) were measured by applying an oscillatory strain of $10 \%$ amplitude (in the linear viscoelastic regime) within a frequency range of $0.01-10 \mathrm{rad} / \mathrm{s}$.

Cell culture experiments. The EFS - Ile-de-France tissue bank (Paris, France) provided organcultured human donor corneas and human amniotic membranes. Three human corneas were used. The average donor age was 76 years (range 66-88 years). Donor death to tissue retrieval time ranged from 7 to 28 hours (18 hours on average). Donor corneas were organ-cultured as described in. ${ }^{38}$ After transplantation of the central part, the remaining corneo-scleral rim was used for cell culture. AM were obtained from female donors undergoing cesarean section.

Superficial limbal explants were prepared as previously described. ${ }^{39}$ Three human limbal rims were divided into 2 parts and each semi-rim was separated into 3 explants. For each donor cornea, 3 explants were cultured for 14 days on the surface of a collagen scaffold (10 mM acetic acid / $0.3 \mathrm{mM} \mathrm{HCl}-90 \mathrm{mg} / \mathrm{mL}$ - fibrillated) and 3 on amniotic membranes used as controls. Collagen scaffolds were first rinsed with Milli-Q water, PBS and culture medium to remove all ammonia residues before cell proliferation testing. Human donor cornea explants were secured with one interrupted suture on top of the scaffolds, epithelial side up as previously described. ${ }^{30}$ The setup was immersed in modified Green's medium. Culture conditions that have been shown to be optimal for expansion of progenitors were used. ${ }^{40}$ The culture medium was changed three times a week. 
After 14-days of culture, the cell sheet area grown on the scaffolds and on the AM were imaged non-invasively with full-field optical coherence microscopy (FFOCM, LLTech, France ${ }^{40,41,42,43,44,45}$ ) to determine the number of cell layers grown on the carriers.

Limbal explants were removed at the end of the culture. Cells grown on both types of carriers were enzymatically dissociated from them with $0.5 \%$ trypsin for 8 min and counted with a Kova Slide after staining with trypan blue to exclude non-viable cells, or carriers were fixed with paraformaldehyde $4 \%$ and then included as a paraffin block and frozen. They were characterized by means of colony formation assay, immunofluorescence and RNA Extraction, Reverse Transcription, and Quantitative Polymerase Chain Reaction (RT-qPCR). The number of replicates performed per type of carrier was 3 .

To determine the clonal growth ability of cultured limbal epithelial cells, a Colony Forming Efficiency (CFE) test was performed as previously described. ${ }^{46}$ Enzymatically dissociated cells grown on each carrier were seeded at a density of 1000 cells/well in twenty-four well culture dishes on $3 \mathrm{~T} 3$ fibroblast feeder layers. Cultures were incubated at $37^{\circ} \mathrm{C}$ under $5 \% \mathrm{CO}$. The colonies were fixed on day 12 and stained by immunocytochemistry. The CFE was defined as the number of cells forming colonies as follows: $\mathrm{CFE}=$ number of cultured cells $\mathrm{x}$ (number of counted colonies / 1000). CFE assays were performed in triplicates.

Immunocytochemical staining was performed on paraffin embedded sections (5 $\mu \mathrm{m}$ in thickness) and on cells colonies as already described. ${ }^{30}$ The following antibodies were used: Cytokeratin 3 (monoclonal antibody Clone AE-5; Dako Trappes, France) as marker of differentiated corneal epithelial cells, and p63 (Cell signaling technology, France) as a marker of limbal stem cells.

Total RNA was isolated from cultured human limbal epithelial cells using the ReliaPrep RNA cell Miniprep System (Promega, France) according to the manufacturer's instructions. The 
amount of total isolated RNA was quantified by optical density at $260 \mathrm{~nm}$. cDNA was reversetranscripted from 1 to $2 \mathrm{mg}$ of total RNA by Quantitect Reverse Transcription Kit (Qiagen, France). Quantitative polymerase chain reaction (qPCR) of $\mathrm{CK} 3$ and $\Delta \mathrm{N}$ p $63 \alpha$ genes was carried out in a $20 \mu \mathrm{L}$ solution containing cDNA, and TaqMan Gene Expression Assay Mix (Applied Biosystems, France). The results of quantitative real time PCR were analyzed by the comparative threshold cycle method and normalized by $\beta$-actin as an internal control. The amount of relative target gene mRNA was expressed relative to the amount present in the reference using the following formula: $2^{-\Delta \Delta \mathrm{Ct}}$.

One-way ANOVA was used to analyze the Colony Forming Efficiency. Donor cornea and carrier used to grow epithelial cells were used as categorical variables. Statistical analysis was performed using a software program (Statistica version 6.1; StatSoft France, Maisons-Alfort, France). Standard errors of the mean are shown on the figures.

\section{RESULTS AND DISCUSSION}

Various physicochemical conditions, based on combinations of acetic and hydrochloric acids, were tested with the ultimate goal to generate transparent dense fibrillated collagen matrices with 3D organizations best closely mimicking the corneal stroma organization. The idea of using such a combination relied on empirical observations showing that collagen behaved differently when purified in acetic acid solution or in hydrochloric acid: solutions in acetic acid led to cholesteric liquid crystal phases, while fibrils were obtained in pure hydrochloric acid. Based on this observation, we decided to explore the effect of mixing the two acids as described in Table 1. Aiming at synthesizing scaffolds mimicking corneal stroma, we prioritized criteria to be achieved. We thus sequentially analyzed: 1) the transparency of the scaffolds, 2) the liquid 
crystal organization and the viscoelastic properties of collagen solutions with different organizations to better understand how these organizations could be maintained when extruded and shaped in glass molds before fibrillogenesis. Finally, we investigated the added value in term of culturing limbal epithelial cell on scaffolds prepared with the condition that we considered best.

Transmittance. Figure 1 shows the transmittance of the collagen scaffolds obtained after fibrillogenesis at $90 \mathrm{mg} / \mathrm{mL}$ as a function of concentrations in acetic acid $\left(\mathrm{CH}_{3} \mathrm{COOH}\right)$ and hydrochloric acid $(\mathrm{HCl})$. A region of high transmittance at low concentration in acetic acid is observed. The highest transmittance $(96.2 \%)$ is obtained under condition 13. High transmittance values $(\geq 85 \%)$ are also obtained under conditions 6-8, 10 and 20 (Fig. 1, Table 1). In general, all scaffolds made at $\mathrm{pH}>2.8$ were transparent, all scaffolds made at $\mathrm{pH}<2.5$ were opaque and, in between, the transparency depended on the mix of acids (Fig. 1, inset).

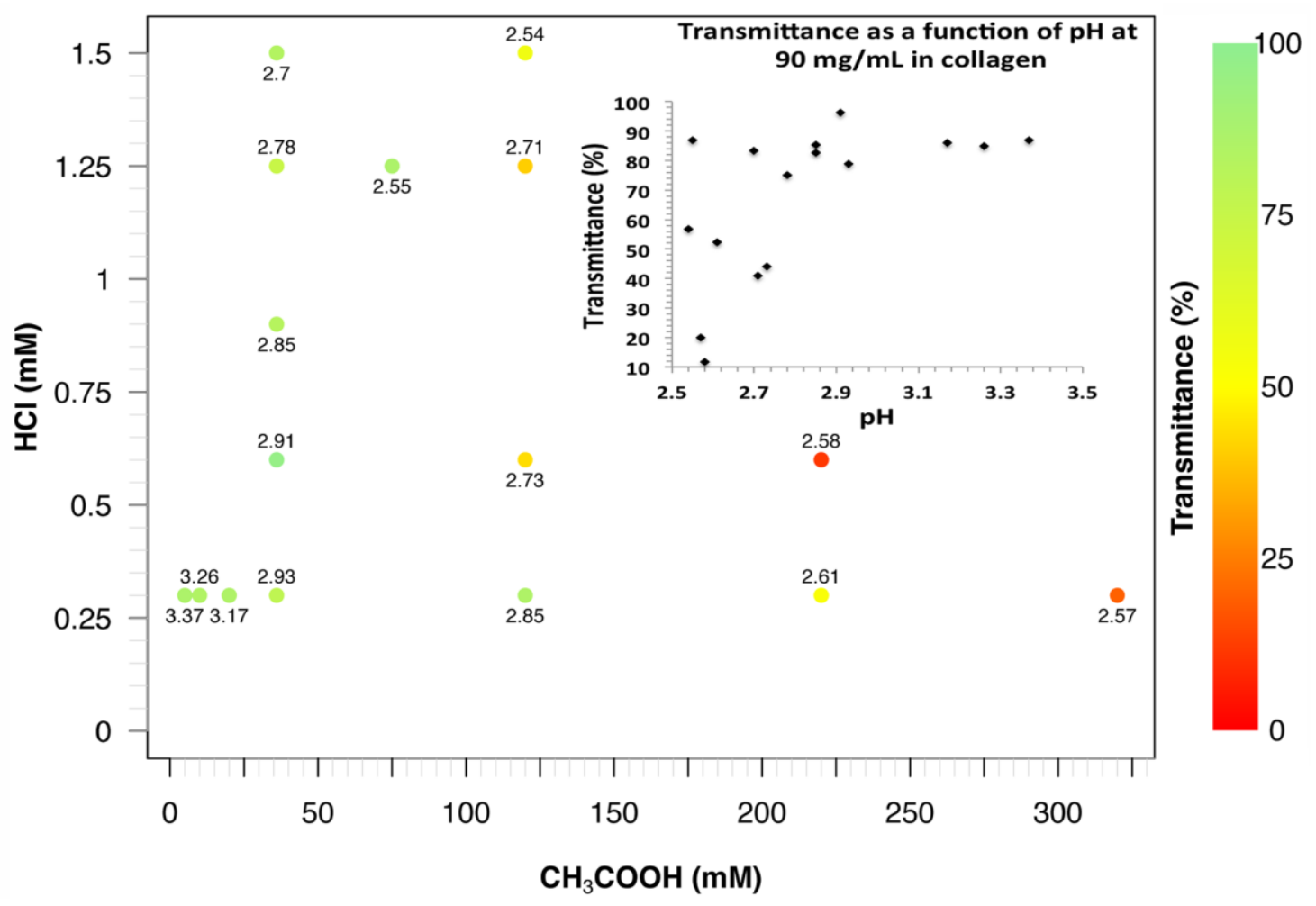




\section{Figure 1. Physicochemical conditions investigated for the synthesis of transparent collagen}

scaffolds. Transmittance of the collagen scaffolds at $90 \mathrm{mg} / \mathrm{mL}$ as a function of the physicochemical condition defined by the concentrations of acetic and hydrochloric acids. The $\mathrm{pH}$ is given for each condition and the transmittance illustrated by the rainbow color code. A distinct region of high transmittance is found for comparatively low concentrations of acetic acid. The inset illustrates the evolution of transmittance as a function of $\mathrm{pH}$.

The influence of the collagen concentration on transparency is shown in Figure 2A for conditions 6-10, 13, 16, 19, 26 (Table 1), which correspond to high transmittance obtained at $90 \mathrm{mg} / \mathrm{mL}$. At a collagen concentration of $60 \mathrm{mg} / \mathrm{mL}$, high transmittance $(\approx 90 \%)$ is achieved with most of the physicochemical conditions. Increasing the collagen concentration from $60 \mathrm{mg} / \mathrm{mL}$ to 90 and 120 $\mathrm{mg} / \mathrm{mL}$ induces a decrease in transmittance whatever the physicochemical condition, the amplitude of the decrease differing from one condition to another.

The effect of the duration of fibrillogenesis, the time during which the sample is submitted to ammonia vapor, was analyzed using a set of 6 samples of condition 19 at $60 \mathrm{mg} / \mathrm{mL}$ as this condition turned out to be the most sensitive to changes in parameters (Fig. 2B). The exposure time had little effect on transparency in the range of 7 to 48 hours. Much longer exposure (120 hours) induced a dramatic decrease in transparency. 

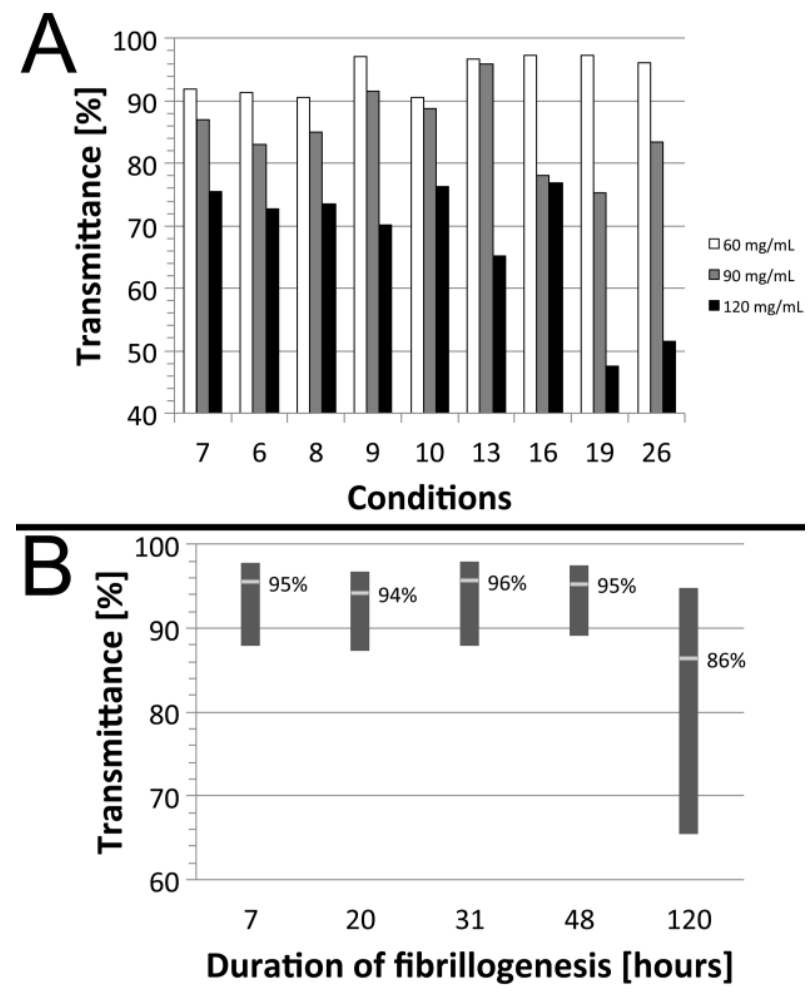

Figure 2. Transmittance as a function of physicochemical conditions and duration of ammonia vapor exposure. A) Transmittance of scaffolds synthetized for different physicochemical conditions at 60, 90 and $120 \mathrm{mg} / \mathrm{mL}$. Transmittance decreases when collagen concentration increases. B) Transmittance of collagen scaffolds fabricated under condition 19 at $60 \mathrm{mg} / \mathrm{mL}$ for different durations of exposure to ammonia vapor. The dark bars represent the transmittance between $380 \mathrm{~nm}$ and $780 \mathrm{~nm}$, the mean transmittance is indicated by the bright marks.

The evolution in transmittance in the storage media was checked over time. Figure 3 presents the results for five matrices synthesized under condition 7. Transmittance varied during the first two weeks and then reached a plateau at $86 \%$. After 60 days, the mean transmittance of the five scaffolds was still $86 \%$, showing the stability of transmittance during this time period. This evolution was also checked using other conditions and showed similar results (Fig. SI-1). 


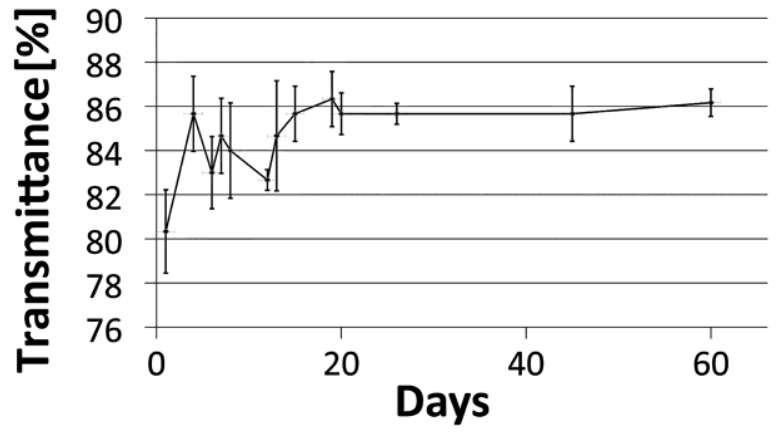

Figure 3. Evolution of transmittance of scaffolds synthesized at $90 \mathrm{mg} / \mathrm{mL}$ with the physicochemical condition 7 . The transmittance increases during the first two weeks and then reaches a plateau. The mean transmittance for this condition was around $86 \%$ after 15 days (5 scaffolds were used). The error bars represent the standard deviation for the 5 matrices. The same behavior was observed with other conditions, and the increase varied with the condition (see Figure SI-1).

Our results showed that low concentration of acetic acid and more specifically solutions at $\mathrm{pH}>$ 2.8 led to scaffolds with high transmittance. This transmittance decreased with increasing collagen concentration and as a function of the physicochemical condition used for the synthesis. The maturation duration (i.e., the time lapse during which matrices remained in water after fibrillogenesis) had also an impact as, for condition 7, variations in transmittance were observed in the first two weeks before reaching a plateau. Noticeably the plateau value was higher than the value obtained the first day immediately following fibrillogenesis. This can be explained by a reorganization, or redistribution, of the collagen molecules from one fibril to another fibril. This suggests that the maturation led to a better distribution of the collagen molecules among the fibrils, leveling out their diameter; molecules escaped the largest fibrils to contribute to the smallest ones, thus homogenizing the fibrils diameter. The increase in transmittance could also 
be due to a limitation of aggregation due to swelling of the scaffold during maturation in water. Interestingly, for non-transparent matrices under condition 11, TEM revealed small fibrils aggregated into star-like nodes of $200 \mathrm{~nm}$ (Fig. SI-2) as opposed to regular large fibrils classically observed. ${ }^{8,11,31} \mathrm{We}$ also observed a maturation process but with a lesser effect on transmittance than in other conditions (5\%-relative increase). In this case, it seems that the molecules engaged into the aggregates cannot disentangle and redistribute. The consequence was the opacity of the matrix. Two weeks seemed to be the time needed for the scaffolds to reach a stable state with no further, or at least slower, molecular reorganization whatever the condition

Condition 13 provided the highest transmittance at $90 \mathrm{mg} / \mathrm{mL}$ (96\%), higher than values reported so far. ${ }^{17,20,22,23}$ Our selected condition 7 gave a mean transmittance value of $87 \%$ over the visible range of wavelengths. This data compared with values obtained by other groups that range between 75 and $90.5 \%{ }^{17,20,22,23}$ and was quite close to the value found for human cornea of $80 \%$ as measured with the same procedure. ${ }^{30}$

Collagen organization. PLM observations were used to check liquid-crystal organizations for conditions leading to good transmittance (conditions 6 and 7, 13, 16 and 20). Figure 4A shows typical fingerprint patterns seen with conditions 13, 16, and 20 when observed under crossed polarizers. These patterns reveal cholesteric organizations. ${ }^{6,47}$ Conditions 6,7 and 8 , conversely to the first three conditions, caused abrupt changes from dark to bright in an alternating pattern as exemplified in Figure 4B. These patterns reveal plywood-like organizations. ${ }^{11,32}$ Among them, condition 7 gave the largest plywood domains in glass microchambers and, as such, was selected for the rest of the study to be closer to the stromal organization. 


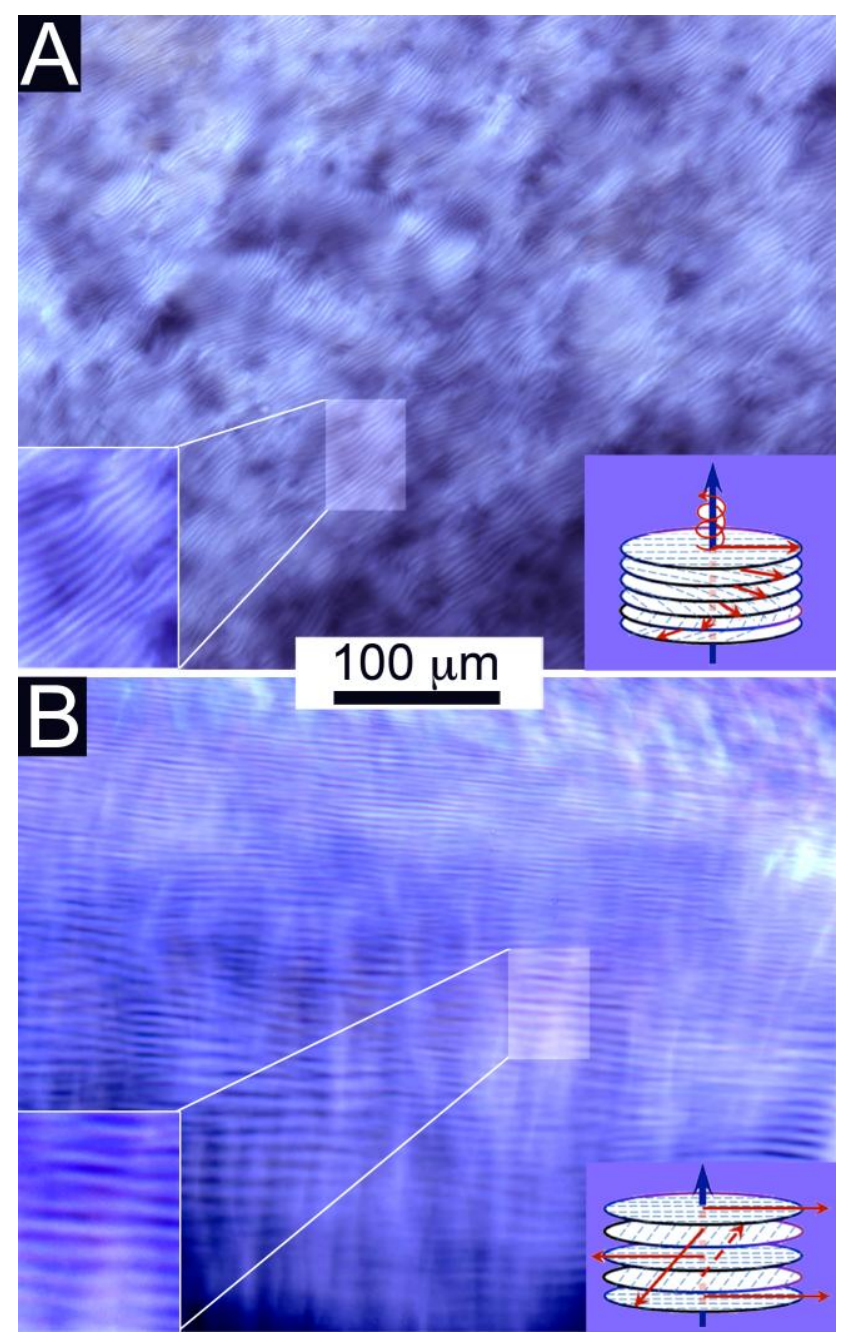

Figure 4. Liquid crystal phases seen through crossed polarizers and interpretation scheme. A) Finger print pattern (cholesteric phase) are observed with conditions 13, 16 and 20 that give transparent scaffolds $(\mathrm{T} \geq 80 \%)$. The insets correspond to the enlightened $50 \mu \mathrm{m}$ width area. In these cases, the molecules are organized helicoidally as illustrated on the inset scheme where discs with molecules symbolized by lines illustrate the rotation of molecular axis. B) Patterns of alternating dark and bright lines (plywood-nematic phase) are observed with conditions 6, 7, 8 . The insets correspond to the enlightened $50 \mu \mathrm{m}$ width area. In these cases, the molecules are all aligned in one direction and the direction of alignment changes more abruptly. 
Figure 5A shows a SHG image of condition 7 in a glass microchamber. It provides a signature that greatly differs from patterns observed previously in conditions leading to cholesteric organizations. ${ }^{48}$ In this condition, straight dark and bright bands alternating over several micrometers were observed with a pitch of approximately $2.5 \mu \mathrm{m}$. In this case, the SHG transverse profile (Fig. 5B, top) was best fitted by Lorentzian peaks. The transverse profile of the 2PEF image acquired in the same region (Fig. 5B, bottom) showed no significant variation, which indicated that the collagen density was homogeneous. ${ }^{32}$
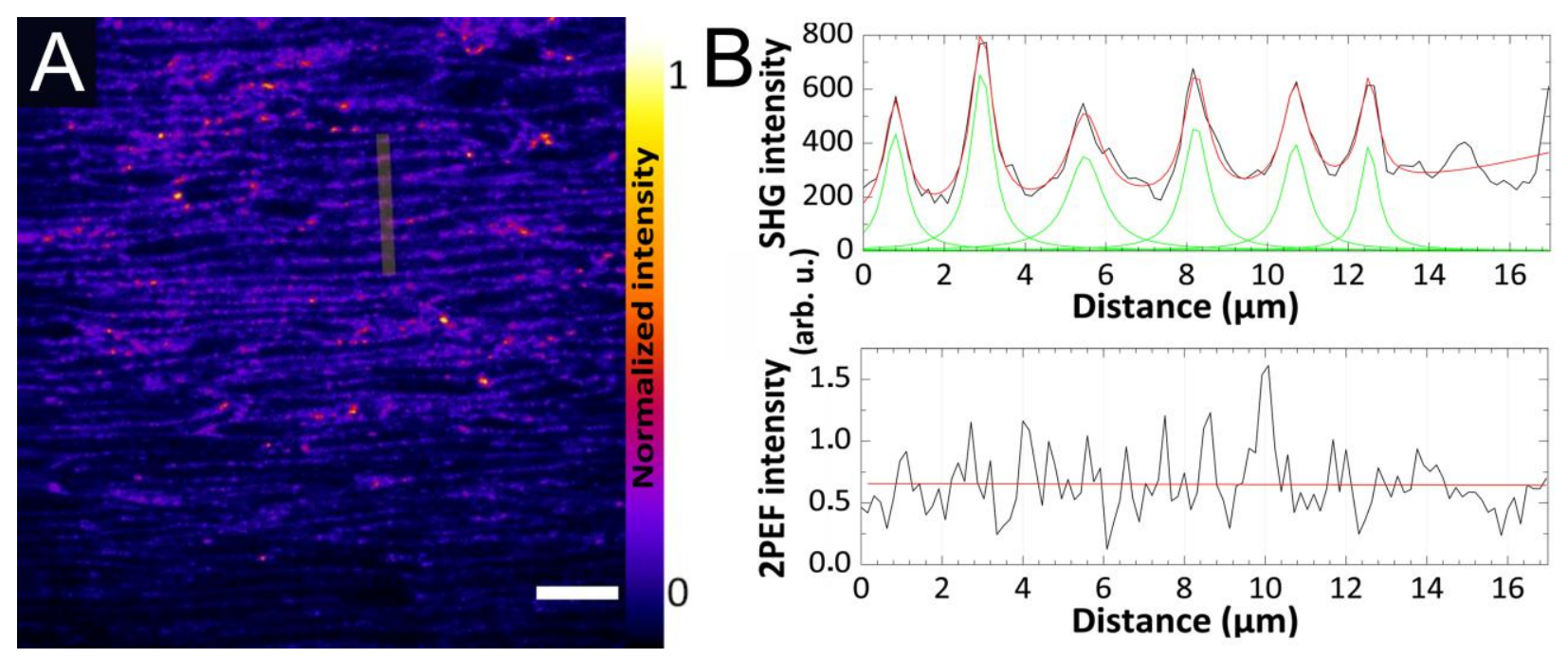

Figure 5. SHG imaging of a liquid crystalline collagen solution in condition 7. (A) Typical SHG image using the displayed Look-Up Table indicated in the colored bar to the right of the image. Scale bar : $10 \mu \mathrm{m}$. (B) $2 \mathrm{PEF}$ and (C) SHG profiles of the region of interest indicated in (A) with a yellow box. The red line in (B) corresponds to linear fitting. The red line in (C) corresponds to fitting with multiple Lorentzian peaks, and the green lines to each of the fitted Lorentzian peaks. 
TEM was performed after fibrillogenesis in solutions concentrated in microchambers under condition 7. It revealed alternating domains with longitudinal and transverse fibrils observed over a few tens of micrometers (Fig. 6A). Scaffolds synthesized in the same physicochemical condition at $90 \mathrm{mg} / \mathrm{mL}$ showed some plywood domains with fibril diameter of around $15 \mathrm{~nm}$ (Fig. 6B).
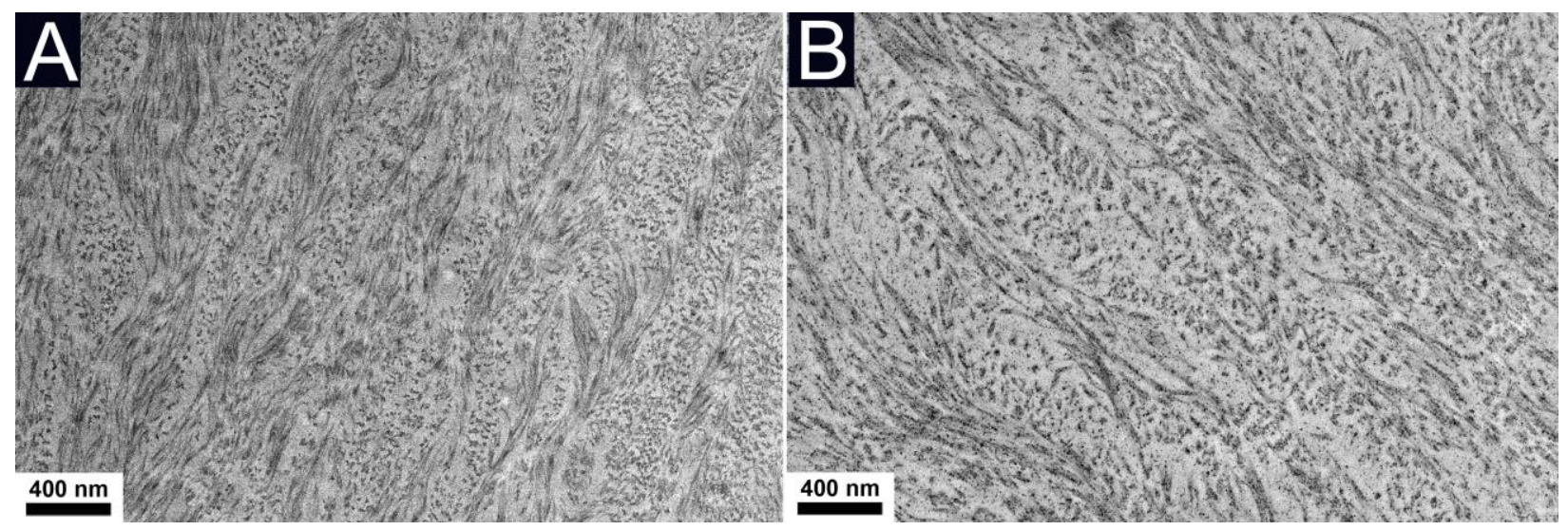

Figure 6. TEM observation of fibrillated samples for condition 7. (A) Matrix formed in a microchamber. (B) Scaffold obtained from $90 \mathrm{mg} / \mathrm{mL}$ concentrated collagen solution.

Conditions 13, 16 and 20, that provided scaffolds of good transmittance ( $\mathrm{T} \geq 80 \%$ ), showed fingerprint patterns characteristic of cholesteric organizations. ${ }^{7,35}$ This proved that the plywood organization was not mandatory to get transparent scaffolds. Conditions 6,7 and 8 led to abrupt changes from dark to bright bands with intensity profiles of the SHG images best fitted by series of Lorentzian peaks, confirming plywood-like organizations. ${ }^{7,32}$ In particular, condition 7, gave the largest plywood domains in glass microchambers. We showed that the critical concentration at which transition from isotropic to anisotropic appeared was around $32-35 \mathrm{mg} / \mathrm{mL}$ similar to the $45 \mathrm{mg} / \mathrm{mL}$ value found by De Sa Peixoto et al. (2011) for condition $1 .^{7}$ Thus, scaffolds need to be synthesized above this concentration to display an organized state. 
The pitch of the plywood corresponds to the distance between two equivalent positions in fibril direction within the lamellae. In cornea, this figure is close to $5 \mu \mathrm{m}$ and in microchambers it ranged from 2 to $4 \mu \mathrm{m}$. Surprisingly, the analysis of the scaffolds by TEM revealed the presence of plywood domains (Fig. 6B) with a pitch of 400 to $800 \mathrm{~nm}$. The alternating layers of fibrils visualized by TEM were also observed on samples prepared in microchambers. Since the pitch changed in the microchambers with the concentration, we could not know which area of the microchambers we actually observed by TEM, impeding the comparison of TEM and optical data. So, we cannot account for the discrepancy between the pitches observed by optical microscopy in the glass microchambers and that observed by TEM. Interestingly, although we molded the concentrated collagen solution to obtain the cornea-like scaffolds, we still observed organized domains. This indicated that: (i) Although the concentration process used for scaffold synthesis was different from that in glass-microchambers, we still generated a plywood organization, (ii) Organized domains displayed sufficient coherence to tolerate, at least locally, the shear induced by molding.

The scaffolds seemed nevertheless to be less organized than expected with regards to the results obtained in microchambers. This cannot be explained by too low a concentration compared to the concentration of phase transition since we worked above $60 \mathrm{mg} / \mathrm{mL}$. It could be due to the differences in the two concentration processes. On the one hand, in the glass microchambers, there was both evaporation and concentration of the solvent during concentration of collagen at the air interface. On the other hand, for scaffold preparation, we used concentrators in which the physicochemical condition remained identical throughout collagen concentration. Moreover, when the concentrated solution was removed from the concentrators and molded, the liquidcrystal organization that appeared during the concentration was destabilized. We should 
emphasize again that, at the end of the whole process, there were still plywood domains in the transparent scaffold. Noticeably, large plywood domains are not mandatory because in the anterior stroma for instance they were described as relatively small $(10-40 \mu \mathrm{m})^{19}$ and, during embryogenesis, as flat bundles of fibrils rather than lamellae. ${ }^{49}$

The fibril diameters $(10-20 \mathrm{~nm})$ observed in our scaffolds were smaller than the diameter of the fibrils found in cornea $(25-35 \mathrm{~nm})$. This showed that the key parameter for the scaffold transparency, at high collagen concentration, was the fibril diameter and the absence of their aggregation rather than the plywood organization. Noticeably, the fibril diameter we obtained was closer to that found in the primary stroma set during the embryogenesis process. ${ }^{50,51}$ It would be interesting to test the benefit of those features for cell colonization on an in vivo model.

Rheology. Rheological measurements were carried on three collagen solutions $(90 \mathrm{mg} / \mathrm{mL})$ prepared in conditions 4, 20 and 7, the two formers leading respectively to transparent and opaque matrices with a cholesteric organization, the latter leading to a transparent matrix with a plywood organization. In all cases, the linear viscoelastic properties showed a power law behavior with a dominant elastic part: $G^{\prime}=K^{\prime} \omega^{\alpha} G^{\prime \prime}=K^{\prime \prime} \omega^{\alpha}$ with $G^{\prime}>G^{\prime \prime}$ as shown in the log-log plot (Fig. 7). This was consistent with the gel-like appearance of the solutions and with our previous study on solutions $4\left(500 \mathrm{mM}\right.$ acetic acid). ${ }^{37}$ Nevertheless, the characteristics of the power-law behavior i.e. the moduli magnitude and the exponent $\alpha$ (the $\log \log$ curve slope) differed from one solution to the other: the plywood solutions exhibited the highest moduli and an intermediate value of $\alpha(\alpha=0.20 \pm 0.01)$ between those of solutions leading to transparent $(\alpha=0.10 \pm 0.01)$ and opaque $(\alpha=0.32 \pm 0.01)$ cholesteric scaffolds.

The exponent $\alpha$ is a measure of the relative degree of dissipative and elastic mechanisms: $\tan (\alpha \pi / 2)=G^{\prime \prime} / G^{\prime}$ with $\alpha=0$ for a purely elastic solid to $\alpha=1$ for a newtonian liquid. The 
oscillatory measurements of the viscoelastic moduli can be interpreted in terms of deformation of the material under load and thus can give us hint of the behavior of the solutions during molding. Indeed, the features of frequency responses in oscillatory measurements correspond to those of time responses in creep measurements through Laplace transform as established by the theory of viscoelasticity. We previously checked $\mathrm{it}^{36}$ for collagen solutions prepared in conditions 4 with viscoelastic moduli scaling as $\sim \omega^{\alpha}$ and strain under load $(\gamma)$ scaling as $\sim \mathrm{t}^{\alpha}$. In addition to a timeindependent and recoverable elastic deformation, collagen solutions thus also underwent timedependent plastic deformation all the more significantly that $\alpha$ was high. Similarly, it has been shown in alginate hydrogels ${ }^{52}$ that an increase of the stress relaxation rate under strain (stress relaxation does not exist in the case of purely elastic material) was correlated with a greater rate of increase of the shear storage modulus with increasing frequency, i.e with a greater value of $\alpha$ the $\log \mathrm{G}-\log \omega$ slope- in the case of power-law behavior: the higher the $\alpha$, the faster the hydrogels remodeled under strain. Comparing the values of $\alpha$ for plywood and cholesteric solutions leading to transparent scaffolds, we thus deduced that the plywood organization enabled faster remodeling during molding than the cholesteric one.

Moreover, in spite of its ability to remodel, the plywood organization kept a high structural cohesion as revealed by its significant elastic modulus, higher than the modulus of the cholesteric organization: this means that, submitted to a stress, the plywood organization exhibits a weaker recoverable strain, resulting from stronger interactions between its constitutive elements. This is consistent with the structural observations of local plywood domains after molding. We previously discussed that plywood organizations obtained in condition 1 (5 mM acetic acid) were stabilized by repulsive interactions between nanofibrils that spontaneously formed at $\mathrm{pH} 3.5 .{ }^{11}$ Moreover cholesteric organizations in condition 4 were also found to be 
dominated by repulsive interactions ${ }^{6}$ but probably between collagen monomers since we did not observe nanofibrils. Springing back elements to their mean inter-distance, repulsive interactions in concentrated systems $(90 \mathrm{mg} / \mathrm{mL})$ are thus consistent with a dominant elastic behavior. Furthermore, our results show that the higher the elastic modulus measured in solutions, the smaller the fibril diameter observed in matrices after fibrillogenesis: 10-15 nm for the transparent plywood organization $\left(\mathrm{G}^{\prime}(1 \mathrm{rad} . \mathrm{s}-1)=5400 \mathrm{~Pa}\right), 20-50 \mathrm{~nm}$ for the transparent cholesteric $\left(\mathrm{G}^{\prime}(1\right.$ rad.s-1)=1430 Pa) and $200 \mathrm{~nm}$ for the opaque cholesteric organization $\left(\mathrm{G}^{\prime}(1 \mathrm{rad} . \mathrm{s}-1)=230 \mathrm{~Pa}\right){ }^{36}$ Strong repulsive interactions in solutions revealed by the highest elastic modulus thus appear to promote numerous nucleation sites and limit nanofibrils aggregation.
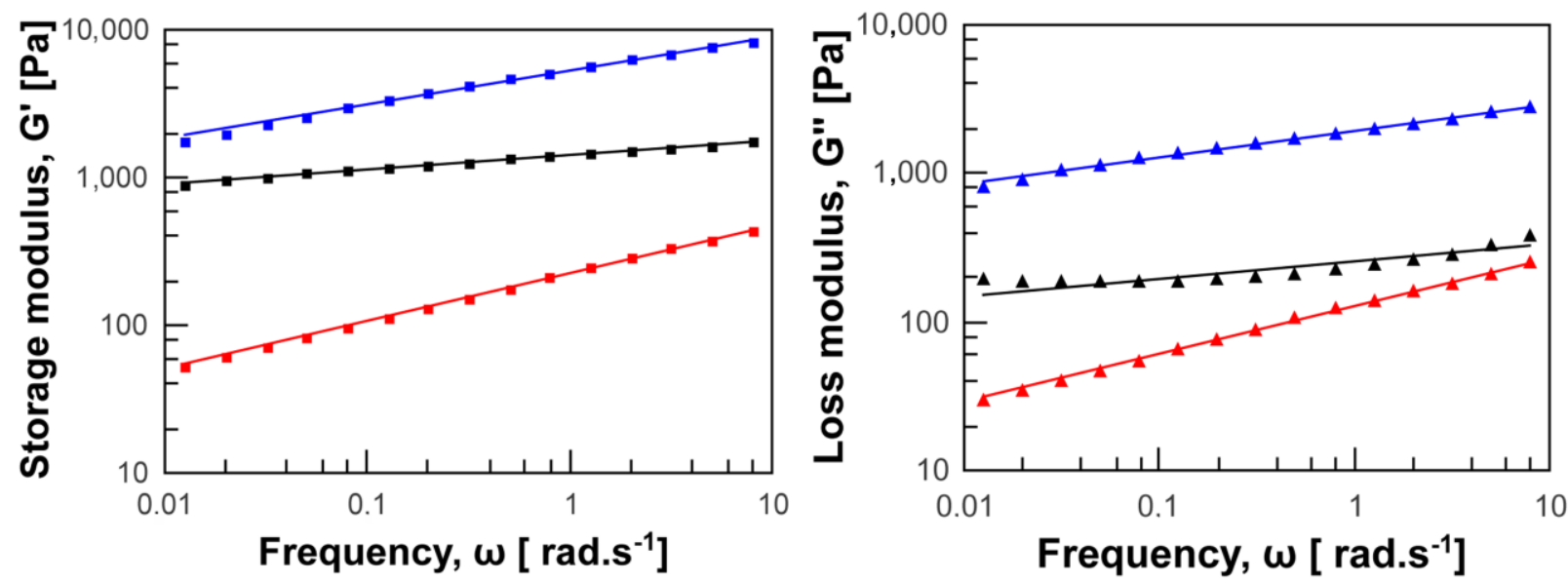

Figure 7. Storage and loss shear moduli of solutions. Solutions prepared in conditions 4 (red), 20 (black) and 7 (blue): $G^{\prime} \sim G^{\prime} \sim \omega \alpha$ with $G^{\prime}>G$ " with $\alpha=0.32 \pm 0.01$ for condition 4 , to $\alpha=0.10 \pm 0.01$ for condition 20 and $\alpha=0.20 \pm 0.01$ for condition 7 .

Cell culture. Limbal explants were cultured on scaffolds synthesized under condition 7 to check their ability to generate a corneal epithelium since they presented the characteristics closest to that of cornea and were compared with cultures made on amniotic membranes. After 14 days of 
culture, layers of cells were observed on both types of carriers with FFOCM (Fig. 8). Four to five layers of cells were observed with epithelial invaginations only observed on amniotic membranes on both types of carrier (Fig. 8).
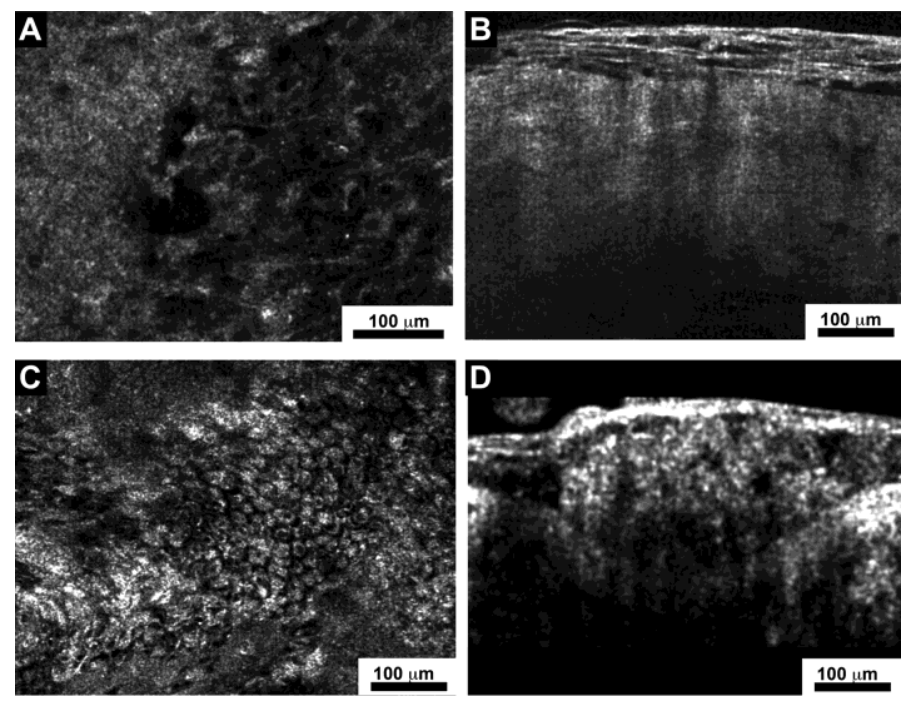

Figure 8: FFOCM observation of cultured limbal epithelial cells. Cells grown on collagen scaffold 7, en face images (A) and cross-sections (B) and on human amniotic membrane (C en face, D crosssections). Four to five cell layers were observed with both carriers. Epithelial invaginations in the carrier were observed only with the amniotic membranes (arrow).

After primary culture, cells grown on both carriers were dissociated and cultured with mitomycin-arrested 3T3 murine feeders for 12 days. The mean Colony Forming Efficiency was, respectively, 1749 and 54 for cells cultured on collagen scaffolds and amniotic membrane (Fig. 9A-D). Cells expanded both on carriers showed strong expression of CK3 as assessed by immunofluorescence (Fig. 9E \& F). Quantitative real time PCR showed transcript expression for $\mathrm{CK} 3$ and $\Delta \mathrm{Np} 63 \alpha$ with higher values for cells grown on collagen matrix compared with cells grown on amniotic membrane (Fig. 9G). 

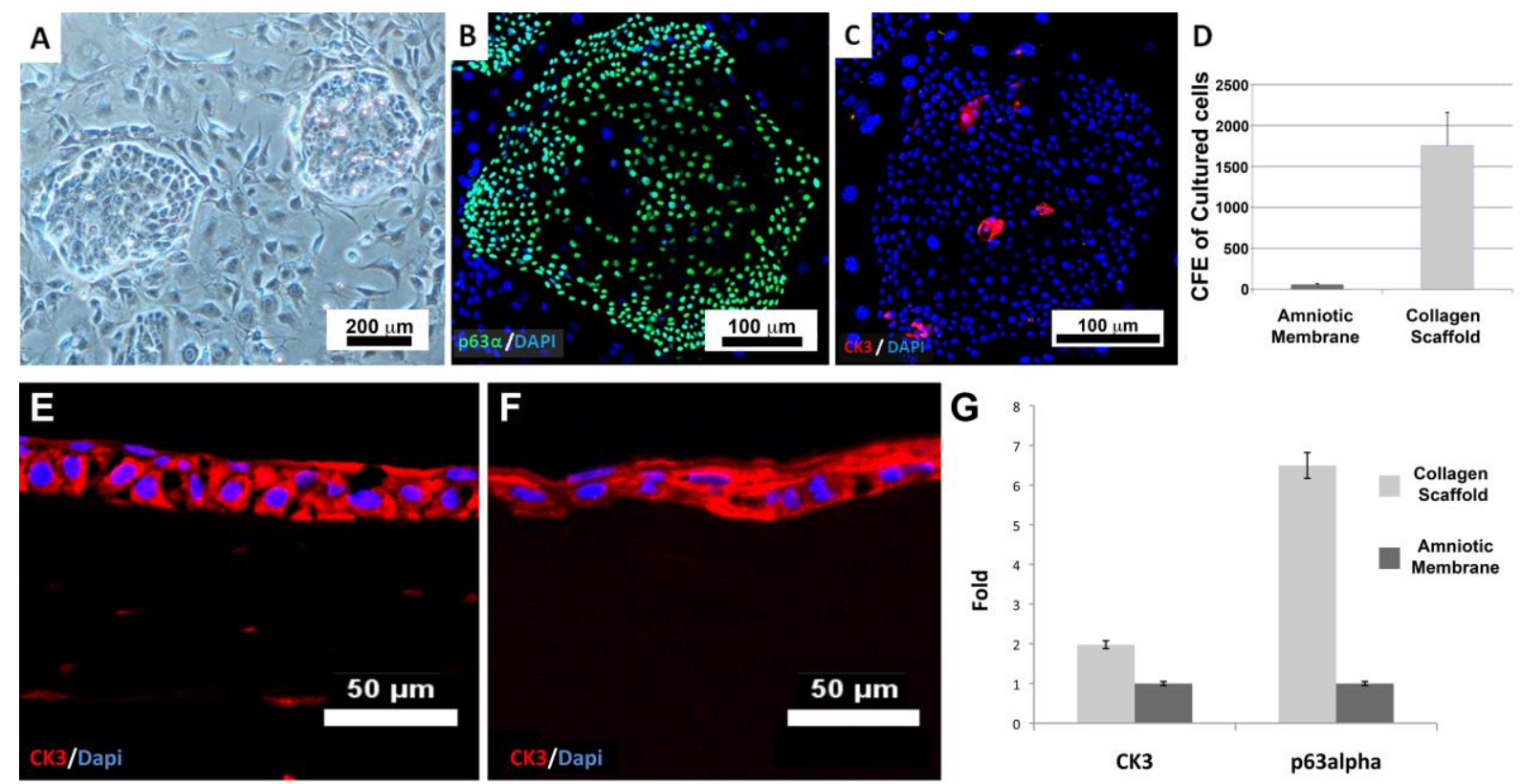

Figure 9: Cells analysis from collagen scaffold and human amniotic membrane. (A) Image of cells forming colonies when cultured on collagen scaffold. (B) Cells in the colony feature positive staining for p63a. (C) Few cells are CK3 positive in the colonies. (D) Colony Forming Efficiency (CFE). A higher number of cells giving rise to colonies was obtained when limbal explants were cultured on collagen scaffolds compared with explants cultured on human amniotic membrane $(\mathrm{p}=0.000026)$. Immunofluorescence staining on paraffin embedded sections of human amniotic membrane (E) and collagen scaffold (F). Cells grown on both carriers featured CK3 positive staining. (G) RNA was extracted from the cells grown on collagen scaffold and amniotic membrane. CK3 and $\triangle \mathrm{Np} 63 \alpha$ mRNA were expressed in cells grown on both carriers.

The results are promising since the colony forming efficiency was higher on scaffolds compared with amniotic membrane, which acted as control. In addition, higher levels of $\Delta \mathrm{Np} 63 \alpha$ mRNA were obtained in epithelial cells grown on collagen scaffolds compared with those grown on 
amniotic membrane. Thus, limbal stem cell expansion was stronger on collagen scaffolds than on amniotic membrane. Our scaffolds, just as human amniotic membranes, supported the growth of corneal epithelial cells since cells featured CK3 expression, a marker of differentiated corneal epithelial cells. Cultured cells maintained their stemness as they still formed colonies and expressed $\Delta \mathrm{Np} 63 \alpha$, a marker of limbal stem cells. Our results compared well to others. For instance, Mi et al. (2013) designed a laminin-coated collagen gel containing keratocytes and demonstrated that it could support limbal epithelial cell differentiation and stratification to an extent comparable to amniotic membrane. ${ }^{52}$ Chae et al. (2015) demonstrated that collagen vitrigel membranes could support corneal epithelial differentiation in a rabbit model, prevented epithelial hypertrophy and could be used as a scaffold from human limbal epithelial cell (hLEC) transplantation. ${ }^{53} \mathrm{Li}$ et al (2014) also demonstrated that chitosan-collagen membranes were suitable for cell differentiation and proliferation. ${ }^{54}$ Thus, our collagen scaffolds that are highly concentrated in collagen and synthesized in absence of cross linkers compare well with scaffolds of various types obtained by other groups. In comparison with our previous work, no significant differences were observed in the maintenance of stemness in the scaffolds obtained with the new physicochemical conditions 7 and those obtained with the previous conditions 20 . These findings indicate that the organization is not mandatory for epithelial cell colonization since it is a surface colonization. However, later on, it may reveal more crucial when dealing with keratocytes.

Finally, our results suggest that our acellular scaffolds could be good candidate as anterior lamellar graft of cornea, firstly because collagen is known for its good biocompatibility and secondly, because we have shown that epithelial cells adhere and proliferate on them. Concerning penetrating keratoplasty or posterior lamellar graft, we have not yet enough data to 
support the real potentiality of our acellular scaffolds. Further studies and especially in vivo evaluation will be necessary.

\section{CONCLUSION}

Physicochemical parameters of the solvent, in which collagen is prepared, control simultaneously the 3D organizations of the scaffold and the diameter of the collagen fibrils at concentrations as high as $90 \mathrm{mg} / \mathrm{mL}$. Rheological investigations reveal differences between solutions leading to scaffolds either with cholesteric or with plywood-like organizations whether transparent or opaque. Collagen solutions prepared in $10 \mathrm{mM}$ acid acetic, $0.3 \mathrm{mM}$ hydrochloric acid and concentrated at $90 \mathrm{mg} / \mathrm{mL}$, lead to plywood liquid-crystal organizations and transparent scaffolds. These solutions exhibit viscoelastic properties that enable molding with relatively fast recovering of the organization prior to fibrillogenesis. The cell culture experiments conducted on these matrices showed very promising results since the cells, originating from human limbal explants, colonized the matrices and differentiated as they do on human amniotic membrane, featuring stemness maintenance and epithelial phenotype. Furthermore, limbal stem cell expansion was stronger on collagen matrix than on amniotic membrane sustaining the idea that those matrices could be of interest for biomedical applications in ophthalmology.

\section{CONFLICTS OF INTEREST}

The authors confirm that there are no known conflicts of interest associated with this publication and there has been no significant financial support for this work that could have influenced its outcome. The method for preparing fibrillar collagen matrix was patented \#WO/2015/049646. 


\section{ACKNOWLEDGMENTS}

The authors thank Bernard Haye and Corinne Illoul for their technical assistance on TEM sample preparation and Frank Wendel for his internship work on the project and Quang Dinh Tran for graphical help. This work was supported by "Fondation pour la Recherche Médicale" (Grant No: DCM20121225759). This work was partly supported by Agence Nationale de la Recherche (contracts ANR-10-INBS-04 France BioImaging and ANR-11-EQPX-0029 Morphoscope2). C. T. was supported by a grant "Contrat Doctoral Spécifique Normalien” from MESR. F.P. was supported by a grant of the Ecole doctorale 397 (Physique et Chimie des Matériaux) and the UPMC.

\section{REFERENCES}

1 D. J. Prockop, Matrix Biol., 1998, 16, 519-528.

2 K. E. Kadler, C. Baldock, J. Bella and R. P. Boot-Handford, J. Cell Sci., 2007, 120, 1955-1958.

3 N. S. Murthy, Biopolymers, 1984, 23, 1261-1267.

4 H. Maeda, Langmuir, 1999, 15, 8505-8513.

5 H. Maeda, Langmuir, 2000, 16, 9977-9982.

6 F. Gobeaux, E. Belamie, G. Mosser, P. Davidson, P. Panine and M.-M. Giraud-Guille, Langmuir, 2007, 23, 6411-6417.

7 P. De Sa Peixoto, A. Deniset-Besseau, M.-C. Schanne-Klein and G. Mosser, Soft Matter, 2011, 7, 11203.

8 C. Helary, A. Foucault-Bertaud, G. Godeau, B. Coulomb and M. M. Giraud Guille, Biomaterials, 2005, 26, 1533-1543.

9 M. Robin, C. Almeida, T. Azaïs, B. Haye, C. Illoul, J. Lesieur, M.-M. Giraud-Guille, N. Nassif and C. Hélary, Bone, 2016, 88, 146-156. 
10 N. Saeidi, K. P. Karmelek, J. A. Paten, R. Zareian, E. DiMasi and J. W. Ruberti, Biomaterials, 2012, 33, 7366-7374.

11 P. De Sa Peixoto, A. Deniset-Besseau, M. Schmutz, A. Anglo, C. Illoul, M.-C. SchanneKlein and G. Mosser, Soft Matter, 2013, 9, 11241-11248.

12 F. Gobeaux, G. Mosser, A. Anglo, P. Panine, P. Davidson, M.-M. Giraud-Guille and E. Belamie, J. Mol. Biol., 2008, 376, 1509-1522.

13 N. Ehlers and J. Hjortdal, in Advances in Organ Biology - The Biology of the Eye., Amsterdam: Elsevier, Amsterdam: Elsevier., 2005, vol. X, pp. 83-111.

14 T. Ihanamäki, L. J. Pelliniemi and E. Vuorio, Prog. Retin. Eye Res., 2004, 23, 403-434.

15 J. R. Hassell and D. E. Birk, Exp. Eye Res., 2010, 91, 326-335.

16 L. J. Müller, E. Pels, L. R. Schurmans and G. F. Vrensen, Exp. Eye Res., 2004, 78, 493501.

17 B. B. Young, G. Zhang, M. Koch and D. E. Birk, J. Cell. Biochem., 2002, 87, 208-220.

18 Y. Komai and T. Ushiki, Invest. Ophthalmol. Vis. Sci., 1991, 32, 2244-2258.

19 F. Aptel, N. Olivier, A. Deniset-Besseau, J. M. Legeais, K. Plamann, M. C. SchanneKlein and E. Beaurepaire, Invest. Ophthalmol. Vis. Sci., 2010, 51, 2459-2465.

20 A. Daxer, K. Misof, B. Grabner, A. Ettl and P. Fratzl, Invest. Ophthalmol. Vis. Sci., 1998, 39, 644-648.

21 K. M. Meek and C. Knupp, Prog. Retin. Eye Res., 2015, 49, 1-16.

22 J. P. Whitcher, M. Srinivasan and M. P. Upadhyay, Bull. World Health Organ., 2001, 79, 214-221.

23 H. F. Chew, B. D. Ayres, K. M. Hammersmith, C. J. Rapuano, P. R. Laibson, J. S. Myers, Y.-P. Jin and E. J. Cohen, Cornea, 2009, 28, 989-996.

24 C. R. Hicks, G. J. Crawford, J. K. Dart, G. Grabner, E. J. Holland, R. D. Stulting, D. T. Tan and M. Bulsara, Cornea, 2006, 25, 1034-1042.

25 X. Calderón-Colón, Z. Xia, J. L. Breidenich, D. G. Mulreany, Q. Guo, O. M. Uy, J. E. Tiffany, D. E. Freund, R. L. McCally, O. D. Schein, J. H. Elisseeff and M. M. Trexler, Biomaterials, 2012, 33, 8286-8295.

26 W. Liu, C. Deng, C. R. McLaughlin, P. Fagerholm, N. S. Lagali, B. Heyne, J. C. Scaiano, M. A. Watsky, Y. Kato, R. Munger, N. Shinozaki, F. Li and M. Griffith, Biomaterials, 2009, 30, 1551-1559.

27 X. Zhao, K. Long, Y. Liu, W. Li, S. Liu, L. Wang and L. Ren, J. Appl. Polym. Sci., 2017, 134, 45226. 
28 B. Kong, W. Sun, G. Chen, S. Tang, M. Li, Z. Shao and S. Mi, Sci. Rep., 2017, 7, 1-13.

29 Y. Tanaka, K. Baba, T. J. Duncan, A. Kubota, T. Asahi, A. J. Quantock, M. Yamato, T. Okano and K. Nishida, Biomaterials, 2011, 32, 3358-3366.

30 A. Tidu, D. Ghoubay-Benallaoua, B. Lynch, B. Haye, C. Illoul, J.-M. Allain, V. M. Borderie and G. Mosser, Acta Biomater., 2015, 22, 50-58.

31 G. Mosser, A. Anglo, C. Helary, Y. Bouligand and M.-M. Giraud-Guille, Matrix Biol., 2006, 25, 3-13.

32 A. Deniset-Besseau, P. De Sa Peixoto, G. Mosser and M.-C. Schanne-Klein, Opt. Express, 2010, 18, 1113-1121.

33 A. Zoumi, A. Yeh and B. J. Tromberg, Proc. Natl. Acad. Sci., 2002, 99, 11014-11019.

34 I. Gusachenko, V. Tran, Y. Goulam Houssen, J.-M. Allain and M.-C. Schanne-Klein, Biophys. J., 2012, 102, 2220-2229.

35 L. Besseau and M.-M. Giraud-Guille, J. Mol. Biol., 1995, 251, 197-202.

36 C. Teulon, A. Tidu, F. Portier, G. Mosser and M.-C. Schanne-Klein, Opt. Express, 2016, 24, 16084-16098.

37 F. Gobeaux, E. Belamie, G. Mosser, P. Davidson and S. Asnacios, Soft Matter, 2010, 6, 3769-3777.

38 V. M. Borderie, S. Scheer, O. Touzeau, F. Vedie, S. Carvajal-Gonzalez and L. Laroche, Br. J. Ophthalmol., 1998, 82, 382-388.

39 D. Ghoubay-Benallaoua, E. Basli, P. Goldschmidt, F. Pecha, C. Chaumeil, L. Laroche and V. Borderie, Mol. Vis., 2011, 17, 341-354.

40 W. Ghouali, K. Grieve, S. Bellefqih, O. Sandali, F. Harms, L. Laroche, M. Paques and V. Borderie, Curr. Eye Res., 2015, 40, 526-534.

41 D. Huang, E. A. Swanson, C. P. Lin, J. S. Schuman, W. G. Stinson, W. Chang, M. R. Hee, T. Flotte, K. Gregory, C. A. Puliafito and J. G. Fujimoto, Science, 1991, 254, 1178-1181.

42 E. Beaurepaire, A. C. Boccara, M. Lebec, L. Blanchot and H. Saint-Jalmes, Opt. Lett., 1998, 23, 244-246.

43 A. Dubois, L. Vabre, A.-C. Boccara and E. Beaurepaire, Appl. Opt., 2002, 41, 805-812.

44 K. Grieve, D. Ghoubay, C. Georgeon, O. Thouvenin, N. Bouheraoua, M. Paques and V. M. Borderie, Exp. Eye Res., 2015, 140, 75-84.

45 K. Grieve, C. Georgeon, F. Andreiuolo, M. Borderie, D. Ghoubay, J. Rault and V. M. Borderie, Cornea, 2016, 35, 1621.

46 D. Ghoubay-Benallaoua, O. Sandali, P. Goldschmidt and V. Borderie, PLoS ONE, 2013, 
8, e81965.

47 N. H. Hartshorne, in Liquid Crystals \& plastic crystals, 1974. G.W. Gray \& P.A. Winsor, England, Ellis Horwood limited., vol. 2, pp. 24-61.

48 P. De Sa Peixoto, A. Deniset-Besseau, M.-C. Schanne-Klein and G. Mosser, Soft Matter, 2011, 7, 11203-11210.

49 R. L. Trelstad and A. J. Coulombre, J. Cell Biol., 1971, 50, 840-858.

$50 \quad$ J. B. Bard and M. K. Bansal, Development, 1987, 100, 135-145.

51 J. B. L. Bard, M. K. Bansal and A. S. A. Ross, Development, 1988, 103, 195-205.

52 S. Mi, V. V. Khutoryanskiy, R. R. Jones, X. Zhu, I. W. Hamley and C. J. Connon, J. Biomed. Mater. Res. A, 2011, 99A, 1-8.

53 J. J. Chae, W. McIntosh Ambrose, F. A. Espinoza, D. G. Mulreany, S. Ng, T. Takezawa, M. M. Trexler, O. D. Schein, R. S. Chuck and J. H. Elisseeff, Acta Ophthalmol. (Copenh.), 2015, 93, e57-e66.

54 W. Li, Y. Long, Y. Liu, K. Long, S. Liu, Z. Wang, Y. Wang and L. Ren, J. Biomater. Sci. Polym. Ed., 2014, 25, 1962-1972. 